\title{
O mundo da vida e a generalização da crise
}

\section{José Manuel Santos}

Como escreveu o sociólogo Niklas Luhmann, "o mundo da vida foi uma das invenções verbais que mais sucesso tiveram neste século". Passados uns escassos quinze anos depois da redaç̧ão destas linhas, e virada que foi a página do século em que foram escritas, nada leva a crer, por enquanto, que o conceito criado por Edmund Husserl, para resolver alguns problemas centrais do seu projecto filosófico, tenha perdido a sua surpreendente capacidade de gerar interrogações. Apesar de não haver nenhum comentador que não encontre na Lebenswelt "ambiguidades" (Claesges), "mal-entendidos" (Blumenberg) ou "contradições" (Luhmann), este conceito toca sem dúvida num ponto nevrálgico da experiência do homem moderno. Só isso pode explicar um sucesso que se estende para além das fronteiras da filosofia. Parafraseando Hegel, poderíamos dizer que Husserl traduziu neste conceito uma inquietude profunda da época. E fê-lo, paradoxalmente, pretendendo apresentar uma terapia da "crise" que está na origem dessa inquietude.

Poucos são, hoje, os que ainda crêem nas esperanças terapêuticas que Husserl associava à Lebenswelt. Isto não põe em causa, porém, as suas surpreendentes virtudes diagnósticas e heuristicas para reflectir a "crise". O presente estudo apresenta as reflexões de três autores - Ludwig Landgrebe, Hans Blumenberg e Niklas Luhmann que prosseguiram o trabalho do pensamento iniciado pelo mestre de Freiburgo com a "invenção" da Lebenswelt. Sâo autores que procederam a uma decantação crítica, a um afinamento teórico deste conceito. Trata-se, para eles, de o utilizar para pensar uma crise de certo modo mais geral do que aquela, por assim dizer pontual, que Husserl acreditava ter localizado no coração das "ciências europeias".

\section{Landgrebe: a experiência original da ameaça}

Em 1949, Ludwig Landgrebe, que havia sido Forschungsassistent de Husserl, e, nesta qualidade, conhecia muito bem os textos da última fase do mestre de Freiburg, protagoniza uma primeira crítica à teoria do mundo da vida. Husserl teria introduzido na descrição da Lebenswelt elementos da "consciência científica moderna", caindo assim numa espécie de petitio principii da descrição fenomenológica:

"Enquanto modo como o mundo, como um todo, aparece à consciência pré-filosófica, Husserl apresenta apenas e somente a consciência do progresso ilimitado possivel da experiência, uma consciência que não pode esconder a sua origem numa relação ao mundo condicionada pela consciência científica moderna"'.

1 "Als die Weise, in der Welt als Ganzes schon im vorphilosophischen Bewußtsein in den Blick tritt, führt Husserl ausschließlich das Bewußtsein des möglichen grenzenlosen Fortgangs der 
Nesta sua crítica da teoria husserliana, Landgrebe descrimina bastante bem os predicados do mundo da vida que se pretende encontrar, os quais estabelecerão entre si tensões dificilmente sustentáveis que darão aso a denúncias de "ambiguidades" ou mesmo "contradições" da parte de comentadores posteriores². A principal tensão é aquela que se estabelece entre um mundo que se deve apresentar "como um todo", de forma a englobar cada uma das minhas experiências para lhes dar sentido, e o carácter processual dessa mesma experiência, concebida por Husserl - a partir do paradigma da percepção - como uma sequência de actos potencialmente infinita. Parafraseando o título de um livro famoso de Alexandre Koyré, podemos formular o problema visto por Landgrebe na teoria do seu mestre como o da tensão entre um mundo que, para ser mundo da vida, deveria ser finito, devido aos pressupostos antropológicos e semânticos de um tal mundo, e uma experiência potencialmente infinita.

O conceito de "horizonte", central na fenomenologia husserliana, está no âmago desta tensão. Tal como ele é introduzido na teoria da percepção do simples objecto, o horizonte marca um limite actual da minha experiência sempre susceptível de ser ultrapassado, transgredido, num "progresso ilimitado". A minha percepção do livro tem como "horizonte externo" o fundo em que o vejo, a estante em que ele se encontra. $\mathrm{O}$ desenrolar das possibilidades da percepção revelam-me, como segundo horizonte, as paredes da sala; esta encontra-se numa casa, que se encontra numa cidade, esta num país, "e por aí fora" (und so weiter). Neste sentido, o mundo seria o último horizonte desta sucessão. Mas como falar de nec plus ultra se a metáfora do horizonte implica justamente, por definição, um plus ultra? É precisamente este Undsoweiter que para Landgrebe constitui o elemento infinitista da "consciência moderna" que teria impedido Husserl de explicitar de maneira clara a sua intuição da Lebenswelt. Este modernismo levar-nos-ia para o beco sem saída de tentar "ver", literalmente, o mundo como um objecto. Ora, o conceito de Lebenswelt designa, antes de mais, um "sistema de remissões" (Verweisungen) da experiência do sujeito, e não o objecto "mundo", "um objecto entre outros objectos", no sentido da cosmologia ${ }^{3}$.

A correcção que Landgrebe tenta introduzir para resolver este problema apoia-se numa característica central do mundo da vida, de que Husserl já fala no texto da Krisis, a qual não levaria necessariamente a uma dinâmica infinitista. $O$ mundo da vida é o mundo da Vertrautheit ou da Selbstverständlichkeit, da "familiaridade" ou da "obviosidade". Neste caso o "horizonte" marca uma linha entre o "familiar" e o "não-familiar", ou o "estranho", o Vertraute e o Unvertraute, cujo grau de mobilidade estaria dependente da dinâmica própria de cada cultura, e, sobretudo, da sua maneira própria de lidar com o "estranho". Poder-se-ia, assim, falar, sem contradictio in adjecto, num "horizonte global" (umfassende Horizont) da experiência no mundo da vida, no sentido em que ele engloba um número limitado de "tipos" de conteúdos, como dirá Husserl,

Erfahrung an, das seine Herkunft aus den Perspektiven eines durch das moderne wissenschaftliche Bewußtsein bedingten Verhältnisses zur Welt nicht verleugnet”. Landgrebe, 1949, 131.

2 "Ambiguidades" é o termo que se encontra logo no título do artigo famoso de Ulrich Claesges, provavelmente a mais rigorosa interpretação puramente interna do conceito em causa: Zweideutigkeiten in Husserls Lebenswelt-Begriff, Claesges, 1972. Niklas Luhmann (1986, 177) fala de "contradição" entre as duas mais importantes metáforas, "solo" e "horizonte", utilizadas por Husserl para descrever o mundo da vida.

3 Landgrebe, 120.

4 Husserl, 1972, 112. O termo Selbstverständlichkeit não é fácil de traduzir. O adjectivo selbstverständlich significa "óbvio", a não confundir com evidente. 
estruturas recorrentes de "remissões" (Verweisungen), ou, se quisermos, em termos semióticos, de códigos, que são a condição prévia da relação do sujeito ao mundo.

Chegados aqui, podemos tematizar o mundo da vida em diferentes direcções, que começaríamos por reagrupar, esquematicamente em duas. Uma primeira, a que poderíamos chamar ontológica, tenta fazer uma classificação dos "tipos" de conteúdos dados em modo de Anschauung (intuição), na tentativa de isolar "tipos" fundamentais, comuns a diferentes Heimwelten, mundos da vida de culturas particulares. É este o caminho platonizante no qual o próprio Husserl dá os primeiros passos. O preço a pagar por uma tal via é a supressão até ao último vestígio do território de "estranheza" que circunda a "familiaridade" do mundo da vida. A "tarefa infinita" da ciência ocidental consistiria, precisamente, na transformação daquilo que, no mundo pré-científico, é simplesmente selbstverständlich, óbvio, em verständlich, compreensível ${ }^{5}$. O problema que se vai colocar é que o "compreensível" não cobre todas as dimensões do "familiar". A experiência do compreender difere, fenomenologicamente, da da obviosidade. Esta última significa que algo ou alguém se comporta de acordo com expectativas previamente formadas. Um "mundo da obviosidade" designaria uma experiência do mundo sem surpresas, expectativas frustradas ou contradições.

Daí que Ludwig Landgrebe, já em 1949, avance para uma teoria da Lebenswelt em cujo centro já não está uma tipologia neutra de simples conteúdos de percepção, mas uma dramatologia da relação ao mundo. A estrutura universal comum aos mundos da vida particulares não é uma tipologia de conteúdos sensíveis, mas algo com a espessura de uma "situação original" (Ursprungssituation): a situação que leva ao traçado da linha de separação entre Vertraut e Unvertraut, entre o "familiar" e o "estranho":

"Se o mundo for o horizonte abrangente da familiaridade, não será o complexo mais original no qual o mundo como um todo é tematizado na vida pré-filosófica o modo do estar-no-mundo no qual esta familiaridade está ameaçada e é posta em causa como um todo? Não constituirá esta ameaça da familiaridade do estar-no-mundo a situação original da existência humana?"6.

Apesar da consonância heideggeriana de um ou outro dos termos utilizados por Landgrebe, o que está aqui em causa não é o primeiro passo de uma "analítica do Dasein" que recorreria à Stimmung de uma "angústia" difusa e sem objecto como o medium hermenêutico privilegiado para revelar o "sentido" da existência. Numa palavra: a "ameaça" tem de ser real e palpável. A "angústia" heideggeriana é moderna, demasiado moderna, e, portanto, simples figura de uma Lebenswelt particular, caindo, assim, sob a crítica de Landgrebe ao particularismo moderno do "infinito".

\section{Blumenberg: a generalização da crise}

Em 1986, o filósofo Hans Blumenberg (1920-1996), na altura autor de uma obra já vasta que começa a ser conhecida para além das fronteiras alemãs, publica um dos seus últimos grandes livros, neste caso dedicado à temática do tempo, subordinado ao título: Lebenszeit und Weltzeit (Tempo da vida e tempo do mundo). Neste livro

Id., 187.

6 "Aber wenn Welt der umfassender Horizont der Vertrautheit ist, ist dann nicht der viel ursprünglichere Zusammenhang, in dem Welt selbst als Ganzes schon im vorphilosophischen Leben thematisch wird, diejenige Weise des In-der-Welt-seins, in der diese Vertrautheit im Ganzen bedroht und in Frage gestellt wird? Ist nicht diese Bedrohung der Vertrautheit des In-der-Welt-Seins, die zu der Ursituation des menschlichen Daseins gehöhrt?" Landgrebe, 1949, 131. Sublinhado por mim (J.M.S.). 
Blumenberg retoma a sua interpretação da obra de Husserl com um subtil e aprofundado estudo do conceito de Lebenswelt. Cabe lembrar que Blumenberg pode ser considerado um discípulo de Ludwig Landgrebe, visto que foi assistente do ex-assistente de Husserl, com o qual completou a sua formação filosófica no imediato pós-guerra, no fim dos anos 40 , início dos anos $50^{7}$.

No seu livro de 1986, Blumenberg retoma, afina e radicaliza a "correcção" introduzida, perto de 40 anos antes, pelo seu "mestre" na questão do "mundo da vida". Tal como em Landgrebe a atitude de fundo não é a de uma rejeição total do conceito a partir de um ponto de vista antagónico, anti-fenomenológico, mas a tentativa de o decantar, de o libertar de uma série de "mal-entendidos" e contradições, que se encontrariam no próprio Husserl, com o fim de pôr a nu a intenção mais original do mestre de Freiburgo.

Tal como para Landgrebe, também para Blumenberg o predicado primeiro, central e, literalmente, essencial da Lebenswelt é a Vertrautheit ou a Selbstverständlichkeit ${ }^{8}$. Isto significa que o "complexo" de experiências que constitui o mundo da vida deve ser analisado exclusivamente à luz da diferença familiar/não-familiar" (Vertrautes/ Unvertrautes), o que exclui, desde logo, toda uma série de oposições conceptuais utilizadas por Husserl (e por muitos outros que usaram o conceito a seguir a ele), tais como: imediato e mediato, pré-científico (ou "primitivo" ou quotidiano) e científico (ou teórico ou filosófico), concreto (ou vital, lebendig) ${ }^{9}$ e abstracto, intuitivo e conceptual, etc. A conjugação da "familiaridade" com os conceitos positivos destas oposições conduziria a contradições. O mundo científico, por exemplo, não é necessariamente não-óbvio (unselbstverständlich) e os mundos das culturas pré-científicas talvez não sejam tão integralmente óbvios (selbstverständlich) como se possa pensar. O pré-científico não é per se "familiar". Por outras palavras, a "familiaridade" não é inerente a determinados conteúdos sensíveis ou categoriais, nem mesmo a determinados mundos particulares. Ela é, antes de mais, uma estrutura da consciência, ou seja decorre de processos pelos quais a consciência se adapta e habitua ao mundo ${ }^{10}$.

Blumenberg justifica o facto de Husserl não ter resistido a um certo uso da Lebenswelt como pedra de arremesso para uma crítica da ciência moderna, motivada pela "perda da magia do mundo" (pela Entzauberung der Welt, deplorada por Weber) e pelo estranheza ligada a uma tecnicização do mundo decorrente das aplicações dessa ciência, pelo contexto histórico em que o conceito de "mundo da vida" surgiu na sua obra. Em termos de logomaquia filosófica a Lebenswelt surge na obra de Husserl, não por acaso em 1927, logo a seguir à publicação de Sein und Zeit, como resposta ao anticientismo radical, assente numa hermenêutica do "estar-no-mundo", do seu assistente Heidegger. Tratava-se, para Husserl, de responder ao "antropologismo" (Husserl) do seu ousado "discípulo" com uma teoria por assim dizer habilidosamente salomónica. A ciência galileana teria as suas culpas no cartório pelo insustentável distanciamento que provocaria na nossa relação com o mundo. Todavia, este efeito não

7 Imediatamente a seguir ao fim da Segunda Guerra, Ludwig Landgrebe foi nomeado professor catedrático da Universidade de Kiel. Foi aí que Blumenberg, orientado por Landgrebe, redigiu as suas dissertações de doutoramento - com o título: Beiträge zum Problem der Ursprünglichkeit der Mittelalterlich-scholastischen Philosophie, concluída em 1947 - e de Habilitation - sobre o tema: Die ontologische Distanz. Eine Untersuchung über die Krisis der Phänomenologie Husserls, concluída em 1950. Infelizmente, apesar da sua grande qualidade, estes trabalhos nunca foram publicados, podendo ser, no entanto, consultados na biblioteca da Universidade de Kiel.

8 Blumenberg, 1986, 25, 41, 49, 59.

9 "O mundo da vida não é um mundo próximo da vida". Id. 21.

10 Id. $59,60$. 
seria inerente à própria ideia de ciência, à sua essência e ao seu telos, antes se devendo a um mau uso dos meios, a um certo facilitismo dos cientistas na sua "prática", que consistiria no uso "técnico", contra-intuitivo, dos instrumentos matemáticos que eles são obrigados a utilizar para pensar a natureza. Deste abuso dos instrumentos conceptuais, sobretudo matemáticos, decorreria uma ocultação das "próprias coisas" por um "manto de ideias" e de "abstracções". Mas estes lamentáveis problemas, até certo ponto compreensíveis, não invalidam completamente o projecto científico da modernidade europeia. Para Husserl eles podem ser fenomenologicamente resolvidos, e o conceito de Lebenswelt pretende ser o pharmakon da funesta "tecnicização" intra-científica que estaria na origem da "crise das ciências europeias" e, de um modo mais geral, da cultura europeia moderna.

Para Blumenberg, esta estratégia husserliana apresenta dois pontos fracos. O primeiro diz respeito à "tecnicização" interna ao próprio pensamento e à pretendida função fundamentadora da Anschauung. Num primeiro ensaio sobre a questão da Lebenswelt", de 1963, Blumenberg tenta mostrar que os efeitos de "tecnicização" são inerentes a qualquer pensamento que se sirva de uma linguagem, sendo a matemática apenas um caso, sem dúvida particularmente exemplar. Se tal é o caso, a exigência husserliana de Anschauung terá de ser fortemente relativizada, a oposição operativa entre conceito puramente "intencional" e Anschauung será, no mínimo, fortemente atenuada. O segundo ponto fraco diz respeito ao próprio conceito de Lebenswelt. Se a diferença específica da Lebenswelt enquanto "mundo", no sentido fenomenológico desta expressão, é a familiaridade ou obviosidade, e se esta propriedade diz respeito a uma estrutura genética da consciência, não se pode dar a entender ou como provado que o mundo "pré-científico" incarna particularmente bem essa estrutura, e que, ainda para mais, as certezas nele adquiridas podem ser facilmente transportadas para o mundo impregnado de ciência da cultura moderna.

Por razões de pura economia, no presente trabalho abordaremos apenas o segundo destes "pontos fracos". Tal como Landgrebe, Blumenberg parte da ideia de uma "situação original" em que surge uma "ameaça" que põe em causa a Vertrautheit, a "familiaridade", do mundo vivido pela consciência. O contributo que Blumenberg dá na sua obra vai ser o de pensar fenomenologicamente em profundidade esta "situação", descrevê-la nas suas linhas gerais, dizer o que poderá ser aquilo a que Landgrebe chama "ameaça", pensar exactamente o que significa uma experiência absolutamente "familiar". Uma teoria da Lebenswelt terá que ter em conta todos os elementos desta Ursituation, a sua estrutura dramatológica e, sobretudo, a possibilidade de esta constituir uma estrutura recorrente na génese da consciência e na história da cultura.

Se o mundo da vida é um mundo da absoluta "familiaridade", ele poderá ser, no âmbito desta estrutura, três coisas. Ou bem é o mundo da experiência da consciência tal como ele existia antes da "ameaça", um mundo em que o Unvertraute nem sequer é pressentido, ou bem um mundo da familiaridade que faz face, mais ou menos imediatamente, a um território do estranho ${ }^{12}$, um mundo que, por conseguinte, já é posterior à "ameaça". Mas será que um mundo que faz face ao estranho, sobre o qual paira uma "ameaça", pode ser considerado um mundo da absoluta familiaridade, uma Lebenswelt? Uma terceira possibilidade, que constitui, aliás, o sonho da fenomenologia

11 'Lebenswelt und Technizierung unter Aspekten der Phänomenologie", in: Blumenberg, 1971, pp. 7-54.

12 A partir de agora utilizaremos de preferência o termo "estranho" como tradução de das Unvertraute, para evitar o uso do "não-familiar", que é mais fiel ao alemão e tem a vantagem de conservar o "familiar", mas que é estilisticamente pouco elegante. 
do último Husserl, seria um mundo em que a consciência venceu as "ameaças", um mundo em que a familiaridade anterior às crises, desencadeadas pelas ameaças, foi integralmente restaurada. Mas será que é possível restaurar in fine a situação de absoluta confiança - outro significado do termo Vertrautheit $t^{13}$-, ou seja restaurar a "verdadeira" Lebenswelt, aquela que precedeu a crise, e, no fundo, todas as crises?

De acordo com a primeira destas três possibilidades interpretativas, o conceito de Lebenswelt designaria a forma mais absoluta de familiaridade, ou confiança no mundo. Fenomenologicamente, a experiência de um tal Ausgangszustand, estado inicial da génese da consciência, só pode ser objecto de uma reconstituição. Mesmo as culturas mais "primitivas" já estariam muito longe de um tal estado, o qual, empiricamente, pode ser situado nos confins do humano, muito próximo da fronteira que separa este da animalidade. Um tal "mundo da vida", escreve Blumenberg, "pode ser descrito como uma esfera de presenças constantes"14. "É possível imaginar uma fase original (es läßt sich eine Urphase vorstellen) na qual o ausente (Abwesendes) era para [o homem] não só indiferente, não só sobretudo desconhecido, mas, antes de mais, não imaginável (nicht vorstellbar)"'15. Um tal mundo não era desprovido de perigos, na presença dos quais o sujeito reagia com mecanismos apropriados de defesa (contra-ataque, fuga, etc.). Mas um perigo não é propriamente uma ameaça. Esta última pressupõe a capacidade de imaginar algo que ainda não está presente, uma consciência antecipativa do ausente e do futuro que ainda não existe na simples reacção pavloviana ao sinal de perigo. Um mundo de puras reacções presencialistas não é apenas pré-científico ou pré-filosófico, mas, mais radicalmente, pré-simbólico (sendo o símbolo algo muito diferente de um sinal), ou seja anterior ao surgimento de todos os "meios" (Mittel) que servem "para tornar presente o ausente: magia, imagens, símbolos, nomes, conceitos" 16 . Todos estes instrumentos já servem para lidar com um ausente ameaçador, com o estranho, com o não óbvio no seu sentido mais estrito. Por conseguinte, um mundo em que exista a imagem, a linguagem, o "símbolo", já não é, por mais "primitivo" que seja, o da pura obviosidade, já não é Lebenswelt no sentido mais rigoroso da definição husserliana. É, pois, compreensível a crítica sistemática de Blumenberg de todas as tentativas, ou tentações, para ilustrar este conceito através de culturas "primitivas", "não europeias", "pré-científicas" ou da "quotidianidade". Levar teoricamente a sério o conceito de mundo da vida como "mundo da Selbstverständlichkeit" significa, fenomenologicamente, avançar com a "hipótese" de um "mundo da adaptação absoluta da consciência" ao mundo. Assim entendido o conceito pode ter duas funções: ou bem designar um mundo que existiu e já não existe de todo, ou bem ser uma "ideia em sentido kantiano", um "conceito-limite" (Grenzbegriff), uma aspiração da consciência que não seria realizável, mas sem a qual ela não poderia viver ${ }^{17}$. Este "ou bem..., ou bem..." não designa, obviamente, uma alternativa. A Lebenswelt é uma coisa e a outra.

Para Blumenberg, o interesse em conceber um mundo pré-simbólico de puras presenças, esse momento que, embora "passageiro na história da humanidade"18, será

13 Vertrautheit vem de vertrauen, que significa "confiar".

14 "Die Lebenswelt ist beschreibbar als eine Sphäre ständiger Anwesenheiten". 1986, 34.

15 Id., ibid.

$16 I d$, 35. A partir desta ideia de símbolo Blumenberg desenvolve uma teoria por assim dizer absentista da linguagem: a função mais interessante da linguagem, a função que permite, entre outros, um discurso como o filosófico, não é uma pura função indicativa, de nomeação de coisas presentes, mas vocativa, de nomeação e vocação do ausente. Cf. id., 37. 1986, 63.

18 Id., 35. 
decisivo para explicar a Ursituation evocada por Landgrebe, não é de natureza antropológica ou paleontológica, mas fenomenológica. Mesmo se ele parece acreditar na sua existência passada, para o propósito teórico do autor: "seria, ao fim e ao cabo, suficiente introduzir apenas a título de hipótese o conceito de um tal mundo de adaptação máxima da consciência aos dados e exigências decorrentes de factores reais, com o fim de estudar neste modelo as possibilidades que ele encerra assim como a sua insustentabilidade"19.

Esta passagem que explicita o objectivo teórico de Blumenberg na sua análise crítica do conceito de Lebenswelt revela alguns traços marcantes da sua fenomenologia. Ela é uma fenomenologia da consciência que alia uma exigência de "realismo" a uma necessidade metodológica especular. Trata-se de reconstituir a "vida da consciência" sem a ideia de encontrar invariantes intemporais, mas na perspectiva das suas reacções a situações "decorrentes de factores reais". Este realismo, tal como aconteceu na fenomenologia de Merleau-Ponty, levará Blumenberg a uma crítica do platonismo do mestre de Freiburgo. Mas o realismo de Blumenberg não é ingénuo (tal como o não é, obviamente, o de Merleau-Ponty). "A realidade enquanto tal (die Realität selbst) é o tema que não é acessível a nenhum realismo"20. O realismo de Blumenberg, por conseguinte, só acede à realidade através da complexidade das reaç̧ões da consciência à "teimosia do mundo", à resistência da sua realidade. A fenomenologia de Blumenberg, que acede à realidade pela via indirecta das reacções da consciência, evita os extremos do realismo ingénuo e do construtivismo radical (por exemplo, de um Luhmann). Num texto dos anos 70 , Blumenberg refere-se à sua própria posição teórica com o conceito de "fenomenologia da história" ${ }^{21}$ - trata-se de uma história das Einstellungen, das "atitudes", da consciência.

Mas voltemos à questão do mundo da vida. No seu sentido mais estrito e absoluto o conceito de Lebenswelt designaria, portanto, uma vivência do mundo antes do surgimento daquilo a que Landgrebe chama "ameaça". Em termos de fenomenologia genética da consciência, a vida num tal mundo seria uma sucessão de presentes absolutos vividos, cada um por si, num horizonte espacial e temporal fechado, "uma vida em que não se põe a questão de saber o que existe no exterior e no depois" 22 . A "ameaça" não é apenas um perigo que se manifesta momentaneamente dentro desse horizonte espácio-temporal fechado, é algo que leva a romper esse horizonte, ao fazer despontar uma inquietude duradoura, formulável como "questão", sobre o que poderá estar "para além" dele. Para Blumenberg, as "experiências originais" (Urerfahrungen) em que se forma a consciência da ameaça são "a escassez (Knappheit) e a morte", as quais "obrigariam a uma outra atitude em relação ao mundo"23. A experiência da morte constituiria, assim, "a primeira figura de um absolutamente desconhecido e indeterminado"24. A partir dela o mundo passa a estar dividido em dois pela linha que separa o "familiar" do "estranho" - e colocar-se-á a questão de saber o que será, neste novo regime, a Lebenswelt.

19 Id., ibid., "Schließliech würde sogar genügen, den Begriff einer solchen Welt optimaler Einpassung des Bewußtseins in die durch reale Faktoren bestimmten Gegebenheiten und Erfordernisse nur hypothetisch einzuführen, um an diesem Modell die darin liegenden Möglichkeiten ebenso wie ihre Unerhaltbarkeit zu studieren".

$20 \quad$ Id. 67.

$21 \quad 1981,6$.

$221986,37$.

23 "Knappheit und Tod sind die Urerfahrungen, die zu einer anderen Welteinstellung [...] zwingen würden". Id., 37.

24 “...die erste Gestalt eines ganz und gar Unbekannten und Unbestimmbaren, vor dem es nichts anders gab als nackte Angst". Id., 36. 
É óbvio que a morte como "factor real" já existia antes da sua "experiência". O que não existia era a consciência do significado da mortalidade. Se, como afirma Aristóteles, o homem é o único animal detentor do lógos, ele também é, por outro lado, o único animal que se sabe mortal. No pensamento de Blumenberg os dois predicados do humano estão intimamente ligados, no sentido em que a linguagem é, para este autor, antes de mais, instrumento de nomeação do ausente e do desconhecido, e a morte, enquanto consciência da mortalidade, é, justamente, experiência de um desconhecido. A significação da morte só pode ser pensada, "constituída" - o mesmo é dizer: a sua experiência só pode ser feita - com o instrumento lógico da negação. Trata-se, pois, de uma experiência negativa no sentido mais literal do termo, ou seja, em que obriga a um acto intelectual de negação, e não num sentido metafórico em que é associada, por exemplo, à dor. A negação aqui em causa reprime a tendência geral (o Streben de fundo) de cada acto de consciência, tendência que é, no fundo, a "sobrevivência" da consciência no acto de "satisfação" (Erfüllung) implicado por cada acto intencional. Encontramos aqui o aspecto processual da vida da consciência, tematizado por Husserl com o conceito do Undsoweiter (do "e-por-aí-fora"). A consciência da mortalidade é a negação absoluta do Undsoweiter, visto que é, como diz Blumenberg, a consciência de um nicht mehr für immer, de um "já não é mais assim para sempre"25.

De certo modo Blumenberg dá razão a Husserl contra Landgrebe, o qual, como vimos acima, havia acusado o mestre de Freiburgo de ter introduzido, na sua tematização da Lebenswelt, com a estrutura processual do Undsoweiter, uma ideia de infinito inspirada pela ciência moderna. A consciência de um horizonte-limite, o uso da negação, mesmo absoluta, não implica a ideia moderna de um "infinito" (teológico, matemático ou físico), mas, quanto muito, justamente, como escreve o autor, a de um "indefinido", um ameaçador "desconhecido" para além do horizonte. Paradoxalmente é a consciência do limite para além do qual está o desconhecido que leva a abrir o horizonte fechado da pura presença, o mesmo é dizer a "sair" do "paraíso" da Lebenswelt. Paradoxalmente, foi uma experiência angustiante que esteve na origem da abertura das possibilidades do humano, e essa experiência foi também a de uma consciência aguda da finitude do tempo da vida. A experiência da mortalidade, ao mesmo tempo que a de um "desconhecido", constitui a consciência de uma incontornável "escassez" do tempo.

Uma vez demonstrado que o conceito de Lebenswelt só se aplicaria, em todo o rigor da sua definição como "mundo da obviosidade", ao "modelo" de um mundo pré-simbólico fechado num presente de puras presenças, Blumenberg vai admitir um uso mais lato, uma flexibilização e, finalmente, um afinamento lógico-filosófico do conceito. Uma vez realizada a experiência crucial da ameaça (acima descrita), uma vez traçada no mundo uma fronteira entre o familiar e o não familiar, o óbvio e o não óbvio, o mundo da vida poderá ser ou bem o território do familiar, ou bem, hipótese mais interessante, um misto dos dois, ou seja, como dirá Luhmann, um mundo em que se joga permanentemente com "a diferença entre o familiar e o não familiar"'26.

Resta, agora, compreender a estrutura da consciência que constitui tanto o familiar como a "diferença". Em fenomenologia genética a intencionalidade da consciência é compreendida, já em Husserl, como um Streben, termo difícil de traduzir que designa uma tendência ou um esforço de fundo da consciência no sentido da sua própria "preservação" (Streben nach Selbsterhaltung) ${ }^{27}$. O Streben realiza-se num processo 
dinâmico de actos, ligados entre si pela correlação entre uma intenção deficitária, ou "vazia", e a sua satisfação ${ }^{28}$ (Erfüllung). Enquanto Husserl pensa habitualmente todo este processo a partir de um paradigma gnoseológico, de um "Eros do conhecimento", que já seria imanente à simples percepção, Blumenberg interpreta a intencionalidade da consciência, de um modo mais geral, como Erwartung, como "expectativa" de qualquer coisa. Todas as nossas experiências, e não só as que se fazem no âmbito do conhecimento científico, são orientadas por "expectativas", ou mesmo por "esperanças", outra tradução possível de Erwartung. Formalmente, a experiência do familiar é aquela em que a cada Erwartung corresponde a respectiva Erfüllung, ou seja em que cada "expectativa" é "satisfeita". Não se trata aqui de satisfazer um desejo; o desejo é algo de arbitrário cada qual pode desejar, por exemplo, a Lua. Desejar a Lua e não a obter não é estranho. Já a "expectativa" do familiar não é arbitrária, visto que é legitimada pela experiência anterior. Estranhos, não familiares, são os objectos, acontecimentos ou pessoas que não se integram no sistema de expectativas, previamente formado, com que cada consciência - ou cada cultura - está armada para enfrentar o mundo.

Aquilo que suporta o mundo da vida é, pois, uma "estrutura de confiança e familiaridade" (Struktur der Vertrautheit) ${ }^{29}$ que se instala na relação de "adaptação" da consciência ao mundo. Neste sentido o conceito de mundo da vida já não designa apenas a "hipótese" de um mundo da "adaptação" absoluta da consciência (que teria existido nos primórdios da humanidade), mas uma estrutura "transcendental" da consciência $^{30}$, uma espécie de sistema imunitário que permite à consciência instalar-se no familiar e defender-se do estranho. Resta saber como.

Num mundo em que, como vimos, já se manifestou a "figura primordial" do estranho, a dinâmica da relação ao mundo vai no sentido de transformar este em familiar. Blumenberg - tal como Luhmann, como veremos a seguir - interpreta a tendência de fundo da consciência e das culturas humanas como um esforço para lidar com o estranho, para integrar o não-familiar. Neste contexto o mundo da vida designa formalmente as diferentes "estruturas de familiaridade", ou seja o conjunto de meios utilizados pela consciência, ou pelas culturas, para tornar o mundo integralmente familiar, ou, dito de outra maneira, para restabelecer o status quo ante relativamente à experiença da "ameaça". A obra de Blumenberg, no pormenor das suas análises de "fenomenologia histórica", é consagrada ao estudo dos grandes momentos e grandes figuras que concretizam esse esforço de familiarização: o mito, a religião, a "teoria" grega, a filosofia, a ciência moderna e a técnica. Cada uma destas figuras corresponde a uma estratégia distinta de familiarização. Todas elas, no entanto, são interpretadas à luz de uma estrutura fenomenológica recorrente, que assenta na dinâmica da intencionalidade da consciência, interpretada como "expectativa".

Convém explicitar algumas ideias centrais da filosofia de Blumenberg, fundamentalmente três, relativas a esta estrutura recorrente. A primeira é que a "estrutura de confiança" que constitui a Lebenswelt não é algo de estático, mas a resultante do trabalho de duas forças antagónicas: um processo de "destruição" natural, que nunca chega ao ponto de ser completa (não pode haver vida sem mundo da vida), é contrabalançado por um esforço constante de "restruturação" de estruturas de

Ou "preenchimento", como alguns tradutores traduzem a Erfüllung, de uma maneira, em nosso entender, demasiado técnica e pouco natural. Não se diz em português "preenchimento" de uma vontade, tendência ou ambição, mas satisfação.

30 Id., 66. 
confiança ${ }^{31}$. A segunda é que o esforço construtivo de familiarização nunca será totalmente bem sucedido, mesmo se tal é o telos da sua ambição (do seu Streben), não só devido a uma erosão ou "destruição" endémica da "estrutura de confiança", mas porque terá sempre por limite aquilo a que Blumenberg chama o "absoluto da realidade" ou a "teimosia do mundo" 32 . Neste sentido o conceito de Lebenswelt torna-se correlativo do de "realidade" (ou de "mundo"); eles designam duas forças contrárias, sendo esta, a "realidade", aquilo que se opõe em última instância ao esforço de familiarização do mundo da vida. O "absoluto da realidade" contém um resto de estranheza irredutível que mesmo, e sobretudo, as estratégias da ciência (moderna) e da técnica não conseguem superar.

A segunda ideia é a que explica o surgimento de novas figuras, ou estratégias, do mundo da vida no seu antagonismo com a realidade. A obrigação teórica da "fenomenologia histórica" é, justamente, explicar como e porque é que surgem, a dada altura, novas estratégias, figuras, ou "atitudes" (na linguagem de Husserl), como a "teoria" (grega) ou a ciência (moderna). A ideia de Blumenberg para responder a estas perguntas, a terceira "ideia central" a que fazíamos alusão, é que cada nova estratégia ou figura surge como reacção a uma experiência dolorosa do estranho, ou, em termos fenomenológicos, à não "satisfação" (Erfüllung) absoluta de uma "expectativa" forte legitimada pela "estrutura de confiança" da Lebenswelt. Numa palavra: cada nova figura constitui a reacção ao falhanço da anterior. Uma tal frustração da expectativa acarreta uma incoerência maior que corresponde a uma crise geral da experiência do mundo, que só uma nova estratégia, assente na formação de um novo sistema de confiança ou familiaridade, poderá superar. Assim, o fenómeno da "crise", diagnosticado por Husserl no âmago das "ciências europeias", é generalizado por Blumenberg a toda a extensão da "vida" da consciência e das culturas. Enquanto que para Husserl, por mais grave que fosse a crise, ela era pontual e tinha, do seu ponto de vista, uma terapia fenomenológica que se pretendia definitiva, para Blumenberg ela é estrutural, constitui o próprio motor da consciência, e as reacções terapêuticas que ela provoca têm como limite absoluto o "absoluto da realidade".

A última questão, genuinamente filosófica, que se coloca, quando se reconhece o limite absoluto de todas as terapias, seria a de saber como "enfrentar a desolação" de uma "vida que deixou de ter as adaptações precisas a um mundo que lhe seja adequado"33. Surge, aqui, na obra de Blumenberg um complemento filosófico no sentido original deste termo, ou seja um complemento que seria da ordem de uma sophia, de uma Weisheit, de uma sageza ${ }^{34}$.

31 1986, 63. Esta concepção põe em causa uma das funções mais importantes, ou mesmo a mais importante, do mundo da vida husserliano: a função de "solo", conjunto de obviosidades inabaláveis, originalmente dadas no modo da Anschauung, que suportariam todas as "certezas" da construção científica, e que serviriam de "terapia" em todos os casos em que surgissem dúvidas. Blumenberg põe implicitamente em causa a tendência de Husserl para "traduzir" a obviosidade, a confiança e a familiaridade em termos de "evidência", "compreensão", "certeza". O óbvio (das Selbstverständliche) e o compreensível (das Verständliche) são coisas muito diferentes. Desta correcção resulta, para utilizar uma metáfora, que enquanto o mundo da vida de Husserl possui um "solo" granítico, o de Blumenberg é algo como uma jangada provisória construída em pleno mar, longe da terra firme.

$321986,67$.

33 "Es geht [...] um die Möglichkeit eines Lebens, das die genauen Passungen zu einer ihm adäquaten Welt nicht mehr hat und mit dieser [...] Desolation fertig geworden ist und zu werden hat". 1986, 63.

34 A filosofia como “jogo de perguntas e respostas", para Blumenberg o contrário da sageza, encontraria, aqui, o seu limite. Cf. 1986, 68. 
Resta-nos tentar compreender, à luz da "fenomenologia da história" de Blumenberg, algumas figuras da familiarização do estranho, tendo em atenção, sobretudo, tanto por uma preocupação de actualidade como por fidelidade ao mestre de Freiburgo, a mais usada na "cultura europeia", ou seja a da ciência.

No caso do mito, pode-se dizer que a simples força poética da linguagem da narrativa teogónica foi suficiente para tornar familiar a estranheza do mundo e da morte. A experiência dolorosa da "escassez do tempo" pôde ser sublimada através de uma transposição do tempo em espaço. A opressiva finitude do tempo é compensada por uma projecção no espaço, o que significa que no mundo do mito a morte é vista como viagem, transporte para o reino dos mortos, migração das almas, etc. $\mathrm{O}$ essencial da estratégia do mito para lidar com o estranho é, pois, em consonância com esta projecção espacial do tempo, o distanciamento. Blumenberg, tal como Luhmann, considera que no mito, a maneira de lidar com o estranho é pô-lo à distância, sem cortar completamente as comunicações com ele (as quais são asseguradas, por exemplo, pela prática de rituais). O estranho é, por assim dizer, respeitado na sua estranheza. A estranheza é mantida, mas deixa de ser traumática. Num tal mundo da vida nem tudo é óbvio, mas encontrou-se um modus vivendi espacial com o não óbvio.

Blumenberg interpreta o surgimento da ciência, sob a forma da teoria grega, como uma reacção de defesa da consciência, face a um transtorno deste modus vivendi, que se teria manifestado sob a forma de uma experiência angustiante. Compreende-se, assim, a crítica insistente de Blumenberg à assimilação "neo-romântica" da Lebenswelt ao mundo "primitivo" ou pré-científico, que é, no fundo, o mundo do "mito". Se o mundo da vida é, ao mesmo tempo, mundo da obviosidade e mundo pré-científico, não se percebe qual é o motivo da passagem ao mundo "científico", à atitude teórica, visto que num mundo do óbvio, por definição, tudo é óbvio e não se colocam problemas "teóricos".

A explicação da passagem do pré-científico ao científico que Husserl dá na Krisis é uma combinação de voluntarismo (a súbita descoberta da "idealidade" pelos gregos), idealismo e "teleologia da razão ocidental", ou seja de expedientes teóricos que, para Blumenberg, escapam às boas regras da descrição da fenomenologia genética. A tarefa desta, assumida pelo filósofo de Münster, é antes a de reconstituir as vivências (Erlebnissé) da crise, ou seja a consciência da "ameaça" relativamente à qual a "atitude teórica" vai ser a reacção. A dinâmica da consciência é reactiva. Só há mudanças, na estrutura profunda de confiança que caracteriza o mundo da vida, quando as "expectativas" da consciência são abaladas por uma perca geral e sistemática da esperança na "satisfação". Foi o que já sucedera na experiência da mortalidade. Agora, nas vésperas do surgimento da atitude teórica, teve de haver uma experiência análoga. Uma tal experiência ter-se-ia dado a partir do momento em que "os anteriores instrumentos de familiarização deixaram de funcionar" ${ }^{35}$. Esta crise não se deve apenas ao facto de os deuses deixarem de cumprir as suas promessas, ou seja a uma simples perca da crença, mas ao factor de contingência introduzido no mundo pelos seus humores. Os "deuses", que deviam resolver o problema da estranheza do mundo, tornaram-se eles próprios num problema senão maior pelo menos tão grande, e, por conseguinte, enfraqueceram a sua função terapêutica. Daí que a teoria, ou a ciência, prossiga, por outros meios, exactamente o mesmo objectivo do mito. O telos confessado da ciência é, para Blumenberg, "erradicar a estranheza do mundo", "produzir uma consciência de segurança e de bem-estar mundano (Weltbehagen)" 
Mas também neste caso se verifica que de boas intenções está o inferno cheio, visto que também a ciência não consegue restituir o "paraíso" perdido da Lebenswelt inicial, enquanto mundo da absoluta obviosidade. Na perspectiva de Blumenberg o qual na questão da ciência, e, por arrastamento, da técnica, ocupa uma original posição muito para além do antagonismo entre a "demonologia" heideggeriana ${ }^{37}$ e a justificação idealista de Husserl - é justamente o conceito de mundo da vida, enquanto "conceito-limite", Grenzbegriff, que serve para compreender porquê. Podemos apontar três razões. A primeira é fornecida por uma fenomenologia da familiaridade e da obviosidade que faz compreender que a falta de Selbstverständlichkeit (de obviosidade) não pode ser inteiramente absorvida por uma produção de Verständlichkeit (compreensão) que é, de um modo geral, a via da ciência. $\mathrm{O}$ facto de algo ser conhecido ou compreendido não o torna absolutamente familiar. Se isto já é verdade para um objecto, ainda o é mais para um "mundo", no sentido de uma cultura, e ainda mais para o "mundo", no sentido do mundo da vida. Aprofundando esta questão, a fenomenologia blumenbergiana do óbvio acaba por revelar um paradoxo por assim dizer sistémico da Lebenswelt. O óbvio é tal, não por ser evidente, mas por não suscitar questões, por não ser questionado ${ }^{38}$. Daqui decorre que a "estrutura de confiança" que constitui o mundo da vida é tanto mais eficaz quanto mais ignorada é - conhecê-la é poder questioná-la; questioná-la é considerar a possibilidade da sua contingência, o mesmo é dizer arruinar a sua função de criadora de confiança. No limite: "quem vive no mundo da vida não sabe nada dele; quem sabe dele deixa de poder viver nele" 39 .

A acrescentar a este efeito erosivo que o saber da Lebenswelt pode ter sobre a estrutura de confiança que um tal mundo encerra - o qual está particularmente concentrado no "saber" das ciências humanas e da filosofia ${ }^{40}$ - existe um efeito não menos paradoxal provocado pelos conhecimentos de ciências que nos informam sobre o "tempo da vida", como a biologia, e o "tempo do mundo", como a astronomia, a física ou a astrofísica. O efeito destes saberes reaviva a "experiência original" da ameaça que é, como vimos, a experiência da mortalidade como consciência de uma escassez insuperável do tempo. É sobretudo através desta experiência da finitude do tempo humano que a consciência é confrontada com a "teimosia do mundo" ou o "absoluto da realidade". Na filosofia de Blumenberg perfila-se, assim, a visão de uma consequência do saber científico que dá origem ao que poderíamos chamar, se a expressão não estivesse já reservada por outros, uma "dialéctica da Aufklärung": Os conhecimentos da ciência moderna não só não permitem superar o trauma da descoberta da sua própria mortalidade, que teria feito o "primeiro homem", como de certo modo o amplificam, ao tornar cada vez mais evidente a discrepância abissal entre as amplitudes do "tempo da vida" humana e do "tempo newtoniano do mundo" - dois tempos que o mito, a religião e o platonismo (antigo e moderno) não tinham grande dificuldade em fazer coincidir.

A técnica moderna, que, na sua essência, é, fundamentalmente, economia de tempo (criando máquinas que evitam "perder tempo", por aceleração das acções humanas, e imaginando métodos de "organização do trabalho" e gestão do tempo, de modo a tentar introduzir o maior número possível de acções no tempo limitado da vida),

37 O termo é utilizado num tom crítico por Blumenberg muito provavelmente a pensar em Heidegger: "Já fomos abundantemente presenteados com ontologias, teologias e demonologias da técnica; isto provocou uma tal fartura que, depois disso, só se desejaria ouvir a palavra "técnica" da boca do técnico". 1981, 9.

38. Um problema central da teoria husserliana da Lebenswelt é que ela acaba por confundir obviosidade e evidência, estranheza e incompreensão.

391986,60 . 
é, para Blumenberg, a reacção, tão compreensível, na sua motivação, como patética, nas suas esperanças desmesuradas, nos seus mitos e ideologias, a este saber.

\section{Luhmann: a estranheza do futuro contingente}

No mesmo ano em que Blumenberg publicou Lebenszeit und Weltzet, 1986, apareceu no Archiv für Rechts - und Sozialphilosophie um artigo de Niklas Luhmann sobre o tema do mundo da vida, intitulado "Die Lebenswelt - nach Rücksprache mit Phänomenologen". Para além das óbvias diferenças de pressupostos nos fundamentos e nos métodos, sobre as quais não nos vamos aqui debruçar, assim como na linguagem e no estilo, entre a interpretação de Blumenberg, que, apesar de todas as correcções de "mal-entendidos", fica dentro dos limites da filosofia e da fenomenologia, e a abordagem. "sistémica" de Luhmann, verifica-se que as reacções destes autores ao conceito husserliano da Lebenswelt apresentam importantes elementos comuns. Está muito próxima, desde logo, a correcção introduzida por ambos no conceito husserliano, assim como o elemento que fica, uma vez afastado o "mal-entendido". Aquilo que em ambos os casos é posto em causa é a solidez da função de "solo" do mundo da vida, que garantiria, nas palavras de Luhmann, um "Immer-schon-gegeben-Sein-des-Vertrauten" - um "desde-sempre-já-estar-dado-do-familiar"41, que seria comum a todos os mundos da vida. Posto em causa este elemento do conceito, fica igualmente comprometida a função terapêutica da Lebenswelt, que era exercida através de uma refundação por retorno ao "solo". O mundo da vida é uma estrutura móvel, permanentemente sujeita, como diz Blumenberg, a um duplo processo de "destruição e restruturação". Luhmann diz a mesma coisa ao afirmar que a "universalidade da reprodução constante do mundo, que acompanha cada passo do progredir de um sentido para o seguinte" (ou em termos husserlianos: que acompanha cada "acto intencional"), "exclui um solo firme", visto que a cada "actualidade que constitui o centro do mundo também pertence o não familiar, o inseguro, o novo, o não consensual"42. Sendo assim, o grande interesse teórico que ambos vêem no conceito de Lebenswelt - e pelo qual ambos prestam homenagem à originalidade da criação de Husserl - é a diferença modal entre o familiar e o estranho, a única que lhe daria coerência. Também Luhmann exclui oposições parasitárias como imediato/mediato ou concreto/abstracto ${ }^{43}$. A questão teórica interessante que resta, para ambos, é pois, nas palavras de Luhmann: "como se constitui a familiaridade?" 44 - sendo a questão complementar: como se lida com o estranho?

A seguinte afirmação de Luhmann soa como uma homenagem a Husserl: "A diferença do mundo da vida (Lebensweltdifferenz) entre o familiar e o não-familiar é a diferença mais antiga e mais original, a diferença primordial, na medida em que ela se condensa em todas as diferenciações (Unterscheidungen) introduzidas posteriormente. A teologia, a metafísica e a lógica vêm depois [...]". De notar, enfim, nesta lista, sem dúvida incompleta, de pontos comuns, que, nas suas análises do mundo do mito, Luhmann chega à mesma conclusão de Blumenberg, segundo a qual a maneira de lidar com uma estranheza omnipresente e imediatamente palpável consistia em operações de

Estando esta última disciplina ou atitude "nos antípodas da Lebenswelt", visto que procede por interrogação radical e sistemática da obviosidade do óbvio, enquanto a vida no mundo da vida é abstinência do questionamento.

Luhmann, 180.

42 Id., ibid.

43 "O concreto pode ser familiar, o abstracto não familiar; no entanto, é precisamente o caso contrário que é o mais provável”. Luhmann, 188.

Id., 180. 
"distanciamento"45. Note-se, de passagem, que se trata de uma estratégia oposta à da "teoria", a qual, como o teórico Husserl refere, traduz o "estranho" em termos de "desconhecido" ou não evidente, e procede a um "ver" aproximado (sentido original do termo theorein), mais exacto, com o objectivo de transformar o indefinido ou indeterminado em conhecido.

Mas o mais interessante do artigo de Luhmann, para quem já conhece Blumenberg, são as análises que tentam responder à questão: "como é que na sociedade moderna se lida com a distinção familiar/estranho?" ${ }^{46}$. É na resposta a esta pergunta que o sociólogo de Bielefeld tece considerações que podem ser lidas como preciosos complementos às análises do fenomenólogo de Münster.

Enquanto que Blumenberg, em consonância com a inspiração fenomenológica do seu pensamento, tematiza as "atitudes" da ciência, do "iluminismo" e de um certo "neo-romantismo", para responder a esta pergunta, Luhmann aborda o problema através de uma teoria dos media, consonante com as suas premissas sistémicas. As duas respostas não são incompativeis, e pensamos que a de Luhmann pode ser objecto de uma transposição fenomenológica.

A escrita, em particular a sua generalização na época moderna, teria sido o meio privilegiado para lidar com o estranho, e, de certo modo, dominá-lo. De que maneira? A escrita é um medium que coloca à disposição de um grande número de receptores "uma enorme diversidade de material semântico familiar e estranho". Desta maneira, "o estranho" (das Unvertraute) é deslocado da sua posição distanciada para ser "incluído na sociedade", coisa que não seria possível "em tal quantidade" em "sociedades mais antigas"47. O medium da escrita serve, assim, para diluir o estranho, atenuando a sua estranheza, e para normalizar, desdramatizar, a diferença familiar/estranho. Uma vez activadas todas as potencialidades do medium escrita, "os problemas que restam serão simples problemas de organização"48, de gestão racional da estranheza do mundo.

Por outro lado, o jogo da comunicação escrita (em particular a partir da descoberta da imprensa e da sua utilização na comunicação de massa) alarga consideravelmente a esfera da intersubjectividade. Na medida em que aquilo que é estranho para mim pode ser familiar para um outro, e em que a comunicação com esse outro, graças à experiência da Einfühlung ("intropatia", já descrita por Husserl), contribui para a redução do estranho, a comunicação escrita indicia a possibilidade de uma redução sem precedentes da estranheza. No limite tende-se a pensar, no regime da comunicação generalizada pela escrita, que, para todo e qualquer estranho, haverá sempre alguém para quem ele é familiar. Todavia, também neste caso o remédio pode ter efeitos secundários potencialmente mais perigosos que a doença. Se a comunicação reduz a estranheza do mundo, ela aumenta a conflitualidade semântica, que pode degenerar em guerra, quando uma comunidade tenta impor a outra os seus "valores" familiares e nega aos "valores" da outra o direito à existência por motivo de estranheza.

Pode-se pensar que o papel que Blumenberg atribui à ciência, na concretização do objectivo de "erradicar a estranheza do mundo", é corroborado pela função "sistémica" que Luhmann atribui à escrita e à comunicação generalizada que ela permite. Acontece, porém, que, tanto para um como para o outro, o objectivo não é totalmente

45 "Nos primórdios da evolução social o não familiar omnipresente e dominante é colocado à distância". "In den Anfängen der Gesellschaftlichen Evolution das ringsum vorherrschende Unvertraute wird auf Abstand gebracht". Luhmann, 184.

46 Luhmann, 188.

47 Id., 187.

48 Id., 189. 
atingido. Para além da estranheza interiorizada no mundo da vida, que é nele objecto de domesticação e "organização", continua a existir uma irredutível estranheza não mediatizável. No caso da escrita isso deve-se ao facto de, "ao lado do sentido fixado por escrito, existir, na Lebenswelt própria de cada um, um estranho imediato, do qual se sabe seguramente que ele não pode ser escrito: os acontecimentos futuros" ${ }^{\prime 49}$. O futuro desconhecido e contingente, obsessivo objecto de especulação, de previsão e programação, ocupa, na sociedade moderna, o lugar do Deus absconditus de que falava Pascal. Dele irradia uma angústia difusa que alimenta essa "retórica da angústia", de que fala Luhmann, que caracteriza o discurso dominante, obsessivamente securitário, da contemporânea consciência infeliz, na sociedade do risco. As utopias e as metafisicas da técnica - em especial as que especulam sobre as "tecnologias da informação e da comunicação" -, que pululam na cultura contemporânea, podem ser interpretadas, se aplicarmos os ensinamentos da fenomenologia de Blumenberg, como a compreensível reacção a essa angústia.

Ao ver na discrepância irredutível entre "tempo da vida" e "tempo do mundo" a última figura, insuperável, da estranheza do mundo, Blumenberg está de acordo com Luhmann em colocar o "estranho imediato" a que devemos, hoje, fazer face, na dimensão do tempo. Só que, para o primeiro, para além da contingência do futuro, aparece a certeza de uma "realidade" que surge "nas margens do mundo da vida" e nos coloca numa situação que não é profundamente diferente da do "primeiro homem", esse primeiro Aufklärer, quando foi expulso, ou, melhor dizendo, se expulsou a si próprio, pelo saber que adquiriu da sua condição mortal, do "paraíso" da Lebenswelt. Dito isto, o famoso conceito que nos deixou Edmund Husserl continua a ser de uma inestimável utilidade para pensar a experiência e as expectativas do homem moderno.

\section{BIBLIOGRAFIA}

BLUMENBERG, Hans, 1981, Wirklichkeiten in denen wir Leben, Reclam, Estugarda.

BLUMENBERG, Hans, 1986, Lebenszeit und Weltzeit, Suhrkamp, Frankfurt.

CLAESGES, Ulrich, 1972, "Zweideutigkeiten in Husserls Lebenswelt-Begriff", in: U. Claesges e K. Held (org.), Perspektiven transzendentalphänomenologischer Forschung, Martinus Nijhoff, Haia.

HUSSERL, Edmund, 1972, Erfahrung und Urteil. Untersuchungen zur Genealogie der Logik, Felix Meiner, Hamburgo.

HUSSERL, Edmund, 1976, Die Krisis der europäische Wissenschaften und die transzendentale Phänomenologie, Martinus Nijhoff, Haia.

LANDGREBE, Ludwig, 1949, Phänomenologie und Metaphysik, Marion von Schröder Verlag, Hamburgo.

LUHMANN, Niklas, 1986, "Die Lebenswelt - nach Rücksprachen mit Phänomenologen", in: Archiv für Rechts- und Sozialphilosophie, Vol. 72, 1986, pp. 176-194 .

${ }^{49}$ Id., ibid. 
